\title{
Bulgarian science reform attacked
}

ISRAEL HAILS STEPS TOWARDS FUNDING AGENCY

Weightier grants for biomedical researchers. go.nature.com/eKJwbJ

Three years after it joined the European Union, Bulgaria is working to improve its ranking as one of the region's lowest overall performers in science. But a proposed law meant to improve research and universities is meeting protests from the scientists themselves.

The law would dismantle the central Higher Attestation Commission, which awards advanced degrees and oversees academic appointments. Instead, universities would be responsible for awarding their own higher degrees, as happens elsewhere in Europe.

Some researchers charge that the move would eliminate quality control of $\mathrm{PhD}$ and postdoctoral work, particularly in the universities that have sprung up recently. Bulgaria had just four universities in 1990, plus a handful of medical and engineering schools. Now there are 53 universities, serving a population of 7.5 million.
Last week, an action group called the Civil Movement for Support of Bulgarian Science and Education presented parliament with a list of demands for changes to the proposed law. They include setting up a system to govern university accreditation before allowing the institutions to award their own higher degrees.

"We agree that this centralized system is archaic, and that universities should be independent," says Oleg Yordanov, a physicist at the Institute of Electronics in Sofia who is involved with the group. "But the commission needs to be replaced with a system that guarantees a minimum quality of academic achievement."

The University of Sofia and the Bulgarian Academy of Sciences, which together account for $\mathbf{9 0 \%}$ of peer-reviewed publications in Bulgaria, have also registered concerns with the government. Bulgaria's minister of science and education, Sergey Ignatov, an Egyptologist, declined to comment.

Mathematician Emil Horozov of the University of Sofia says that it would be
"This centralized system is archaic; universities should be independent." an "enormous problem" if universities were to give out their own higher degrees, as the agency that accredited the new universities is part of a system that brought "our country to ruin". Horozov took over this month as head of Bulgaria's granting agency, the National Research Funds, and he says that he intends to introduce reforms there as well, such as involving foreign reviewers and making the granting procedures fully transparent.

The law passed its first reading in parliament on 18 December and will go through a second round of discussion and a vote in the next few weeks. Alison Abbott 